\title{
Comments upon the classification of infantile polycystic diseases of the liver and kidney, based upon three- dimensional reconstruction of the liver
}

\author{
CAROLINE M. ADAMS, D. M. DANKS, and P. E. CAMPBELL \\ Department of Genetics, University of Melbourne, and Royal Children's Hospital, Melbourne, Australia
}

Summary. Three-dimensional reconstructions of portal tracts of two babies with different forms of infantile polycystic disease of the kidney and liver, and of a child with congenital hepatic fibrosis, have shown important differences between these three conditions. A strong plea is made for the application of this technique, and of microdissection of kidneys, to a large series of cases in order to develop a valid classification of these conditions.

Considerable variation is seen in the renal lesion in infantile polycystic disease (IPD) of the liver and kidney, and several authors (Osathanondh and Potter, 1964; Elkin and Bernstein, 1969; Blyth and Ockenden, 1971) have devised classifications based upon the clinical course and renal pathology. Unfortunately, very little attention has been paid to the liver lesion in these studies. Conversely, authors reporting cases of congenital hepatic fibrosis (CHF) have often included babies with infantile polycystic disease (Kerr et al, 1961), ignoring the obvious differences in the clinical course and the renal lesion.

This paper reports detailed studies of the liver abnormalities in two babies with IPD and in one child with CHF. The differences observed are of such a degree that three distinct conditions must be postulated. Parallel differences in the renal lesions and in other abnormalities present in the patients support this belief.

\section{Materials and methods}

The cases for this study were ascertained by a survey of the necropsy files for the period 1961 to 1970 , inclusive, at three Melbourne hospitals; the Royal Children's Hospital (RCH), the Queen Victoria Hospital (QVH), and the Royal Women's Hospital (RWH). The RCH and the QVH have over $80 \%$ of the paediatric beds in Melbourne (population 2.2 million) and QVH and RWH together delivered 12,000 to 15,000 babies per year during this period. Eleven cases of IPD and one case of

Received 18 February 1974
CHF were ascertained. Ten of the babies with polycystic kidneys were stillborn or died within 24 hours; one baby lived 10 days.

Routine microscopic sections of the liver and kidney from all these patients were studied and three patients were chosen for detailed study - the child with CHF, and two babies with IPD selected because of marked differences in the microscopic appearances of the liver and kidney, and as adequate tissues were available. Similar studies were made on the liver of a baby who died with intracranial haemorrhage and pneumonia at the age of four days and appeared to have a normal liver and kidneys.

The tissues were fixed in $10 \%$ formalin in saline and were embedded in Parawax Plus. Three-dimensional reconstructions were made from a study of 200-300 serial sections of liver cut at a thickness of $6 \mu$ and stained with either a PAS-diastase technique or haematoxylin and eosin. Medium-sized portal tracts were chosen and were projected onto a ground glass screen through the objectives and photographic eye-pieces of a Unitron Universal Camera Microscope U-11. A glass plate $7.5 \times 7.5 \times 0.15 \mathrm{~cm}$ was placed on the screen and the structures within the portal tract were traced onto the glass plate using different colours to distinguish the arteries, veins, bile ducts, and limiting plate of the surrounding liver lobules. The magnification was generally $\times 50$, but was varied when larger or smaller portal tracts were reconstructed.

One structure in the portal tract was chosen as the point of reference and was kept in a constant position on all the glass plates of that reconstruction. The main hepatic artery was generally chosen. Each 10th section was examined and traced so that the distance between two glass plates represented a tissue thickness of $60 \mu$.

The plates were mounted for viewing in a Perspex 


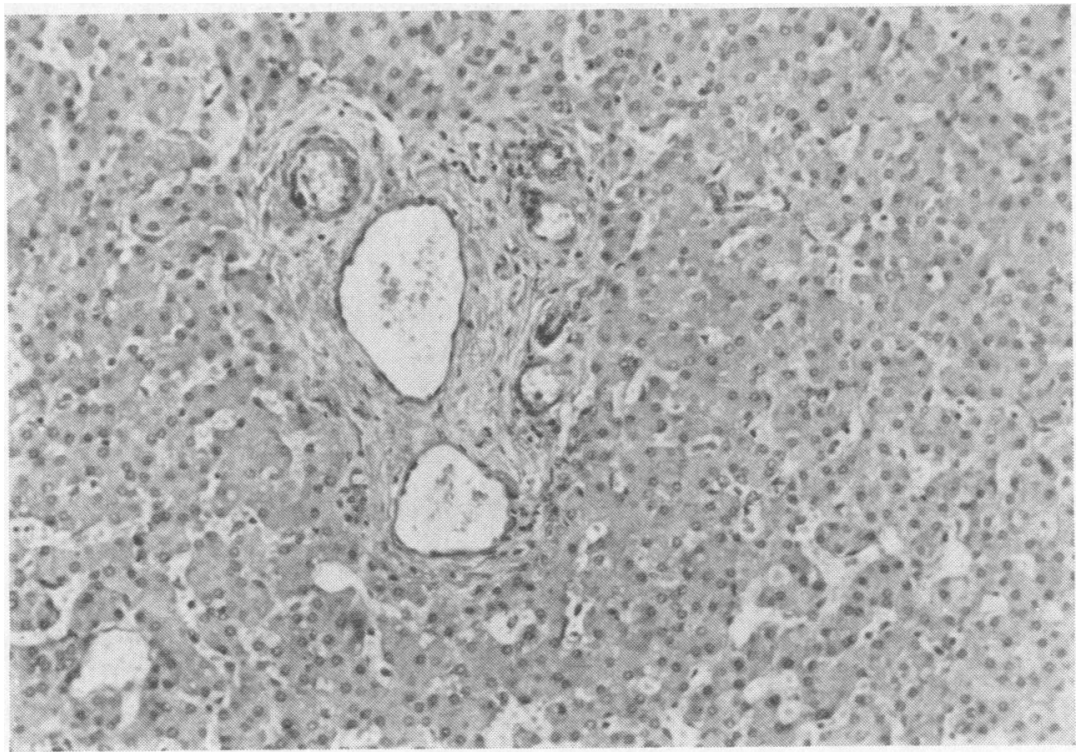

FIG. 1. The normal portal tract which was reconstructed $(\times 130)$.

frame at distances proportional to the distance between the sections. Considerable difficulty was experienced in producing convincing photographs or diagrams of the reconstructions. For this purpose, simplified plates were traced showing only the bile ducts and the limiting plates. Even so, only a small number of sections could be shown in a photograph. Line diagrams were made by tracing several glass plates onto a sheet of paper spaced to give three-dimensional perspective.

The numbers of ducts in a medium sized portal tract were counted in 50 consecutive $6 \mu$ sections to give an objective comparison between the four livers studied.

\section{Results}

\section{Normal control}

A portal tract which was reconstructed is shown in Fig. 1 and a line diagram of the reconstruction is shown in Fig. 2. The main interlobular duct ran a fairly straight course through the reconstruction. The points of entry of smaller ducts were visible as small appendages of ductular epithelium. Small communicating ductules and the longitudinal ductules into which they ran were seen in the limiting plate and at the periphery of the portal tract, respectively. However, the standard reconstruction using every 10th section failed to show communications between the peripheral longitudinal ductules and the main interlobular duct.

Every second section was examined for a small distance at $\times 100$ magnification. Small longitudinal ductules at the periphery of the portal tract, were seen to join into larger longitudinal ductules which were still peripherally placed, and finally into a duct which followed a circular or spiral course to reach the main interlobular duct (Fig. 3). These were the only ducts which were cut longitudinally in transverse sections of the portal tracts.

\section{Infantile polycystic diseases of the liver and kidney (IPD)}

It was obvious that one baby had a form of polycystic disease involving the liver, kidney, and pancreas which differed strikingly from all the remaining cases and resembled closely the patients described by Ivemark, Oldfelt, and Zetterström in 1959. This case was excluded from further consideration. Differences in the degree of ductular proliferation and dilatation were noted which allowed division of the remaining 10 cases into two groups of five babies each.

Confidence in the separation of these groups increased when the kidney sections were examined and revealed two different patterns, and when an occipital meningocoele or encephalocoele was noted in four of the five babies in group 2. Talipes equinovarus was present in four of these babies and one also had a cleft palate. These patients therefore resemble the syndrome described by Meckel (1822). By contrast, no other abnormality was found in the five babies in group 1. Group 2 contained two pairs of sibs whose lesions were very similar indeed. 


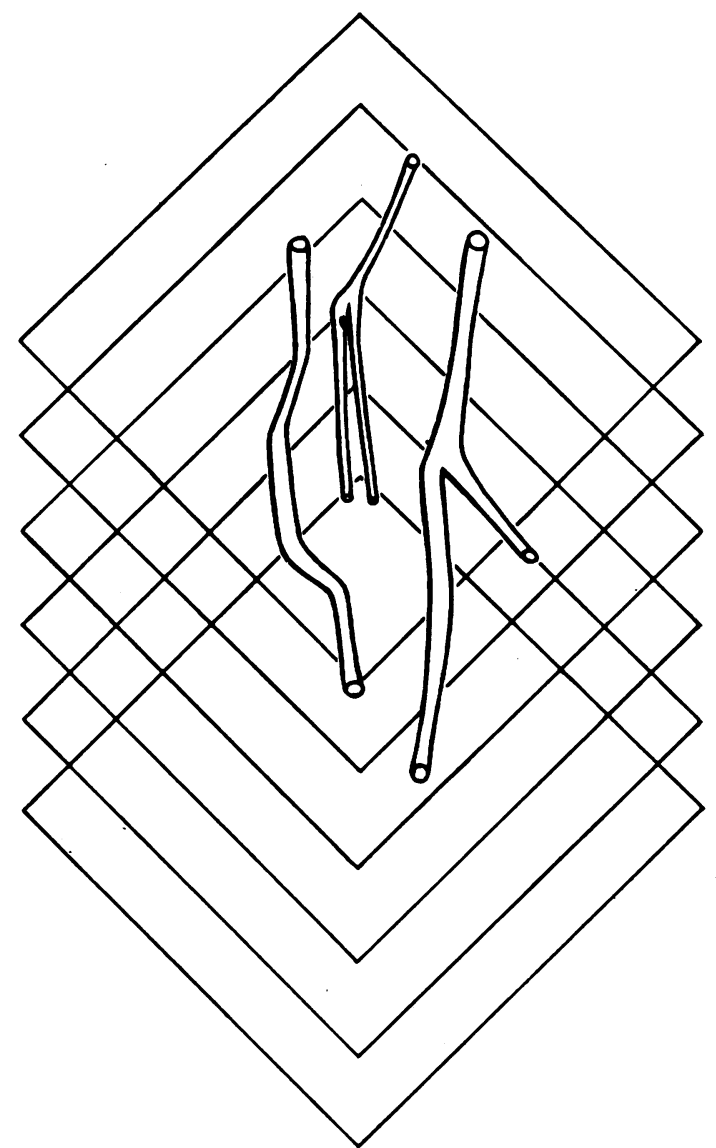

Fig. 2. Line diagram traced from glass plates of every 10th serial section of a normal portal tract. Only those bile ducts which run through at least two plates are shown. Communicating ductules entering from the lobules are not shown and this preparation fails to show any connection between the peripheral longitudinal ductules and the main interlobular duct (at right).

No other familial occurrence was discovered nor any parental consanguinity.

Case 1 (group 1). This female baby was born at 36 weeks' gestation, the second child of a 30 -yearold woman. The baby was slow to recover after a breech delivery, developed respiratory distress, and died at $10 \frac{1}{2}$ hours. Bilateral abdominal masses were noted. The significant necropsy findings were polycystic kidneys, cystic abnormalities of the bile ducts, pulmonary haemorrhage, and prematurity.

The liver. Macroscopically the liver was not enlarged (100 g, normal $105 \mathrm{~g})$. Cysts were visible in the right lobe.

Microscopically the most obvious feature was dilatation and infolding of the bile ducts which were also increased in number (Fig. 4). Every portal tract was affected and nearly all the bile ducts were moderately dilated, forming a confluent channel around much of the periphery of the portal tract. Small groups of dilated and infolded ductules surrounded by a very small amount of connective tissue were also seen within lobules. The ductular epithelium was well differentiated and ranged from cuboidal to columnar, depending on the size of the duct.

The periportal connective tissue was mildly increased but bridging was not seen between portal tracts. The lobular pattern and parenchymal cells were normal. There was no bile retention. The portal tract vessels were normal in size, shape and number. Many foci of hematopoietic tissue were visible.

The kidneys. Both kidneys were greatly enlarged (right $105 \mathrm{~g}$, left $105 \mathrm{~g}$; normal $21 \mathrm{~g}$ ) but the normal shape was maintained. Microscopically they showed the open lacework appearance typical of Potter type I polycystic kidney in which the collecting tubules are greatly enlarged (Fig. 5). The cortex and medulla were filled with oval, elongated cysts of varying sizes, arranged radially. Most cysts were lined with low cuboidal epithelium, but a few lacked any epithelium. In some areas the cysts were close together separated by a little loose $\bar{c}$ connective tissue, but in other areas the cysts were surrounded by quite dense connective tissue. Small foci of normal renal components were visible between the cysts, particularly in the subcapsular region.

The glass plate reconstruction. Irregularly dilated ducts running longitudinally at the periphery of the portal tract anastomosed so extensively that they almost formed a single annular channel. Projections transversed the limiting plates of the surrounding lobules and others protruded towards the axis of tract. However, no main interlobular duct could be identified in this portal tract or in several others from this liver. The dilated ducts were very difficult to display in photographs, but they are traced in Figure 6.

Case 2 (group 2). A male baby born at 39 weeks to a woman of 25 years whose previous two pregnancies had produced healthy girls. Spontaneous labour terminated with the assisted breech delivery of a stillborn boy. Her next pregnancy produced another boy who died of the same disease. The significant necropsy findings were polycystic 


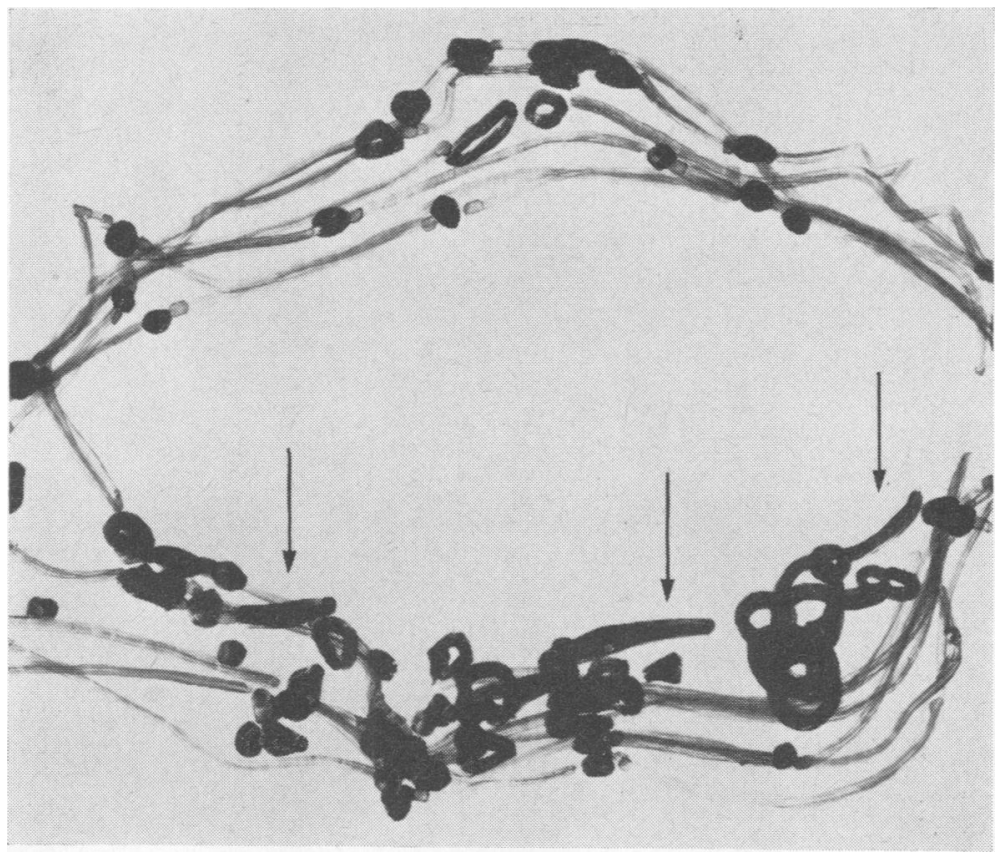

Fig. 3. Axial photograph of five plates traced from alternate serial sections of a normal portal tract. The arrows indicate ductules running a circular course to connect the peripheral longitudinal ductules with the main interlobular duct. Each longitudinal duct is seen in each of the five plates, and some communicating ductules are shown, creating an impression that there are far more ducts than in Fig. 2.

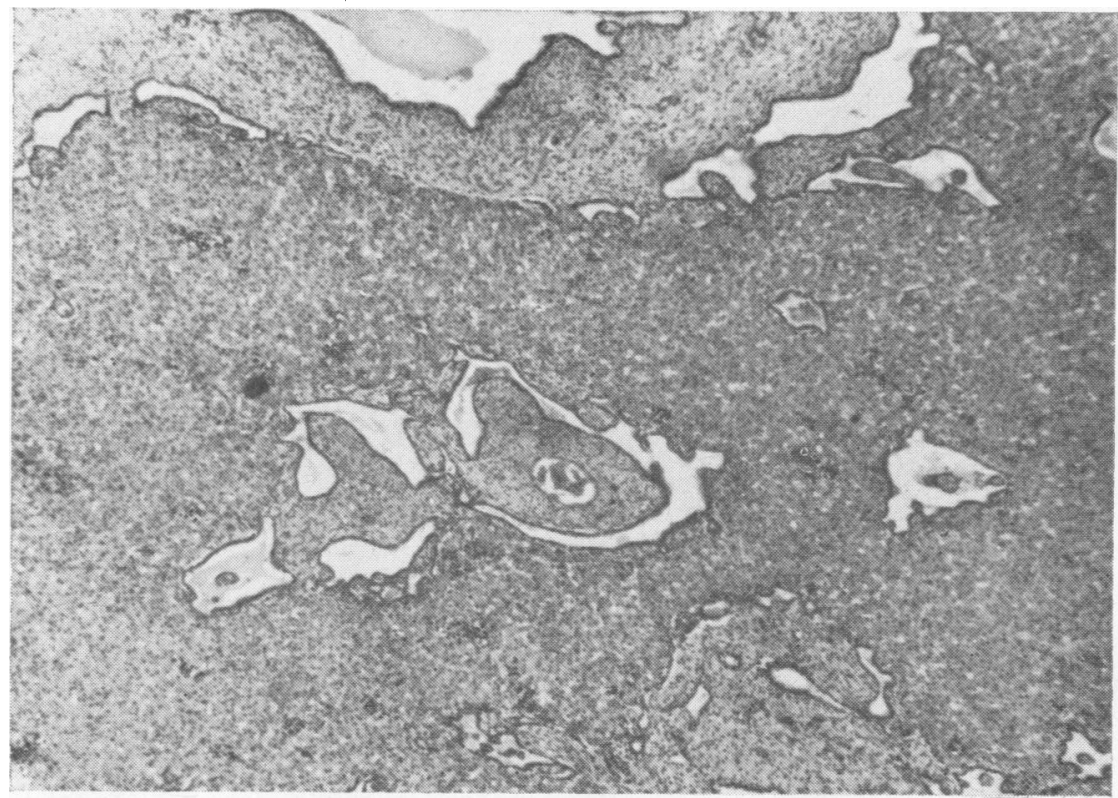

Fig. 4. Case 1. The portal tract which was reconstructed. The bile ducts show dilatation and infolding $(\times 45)$. 


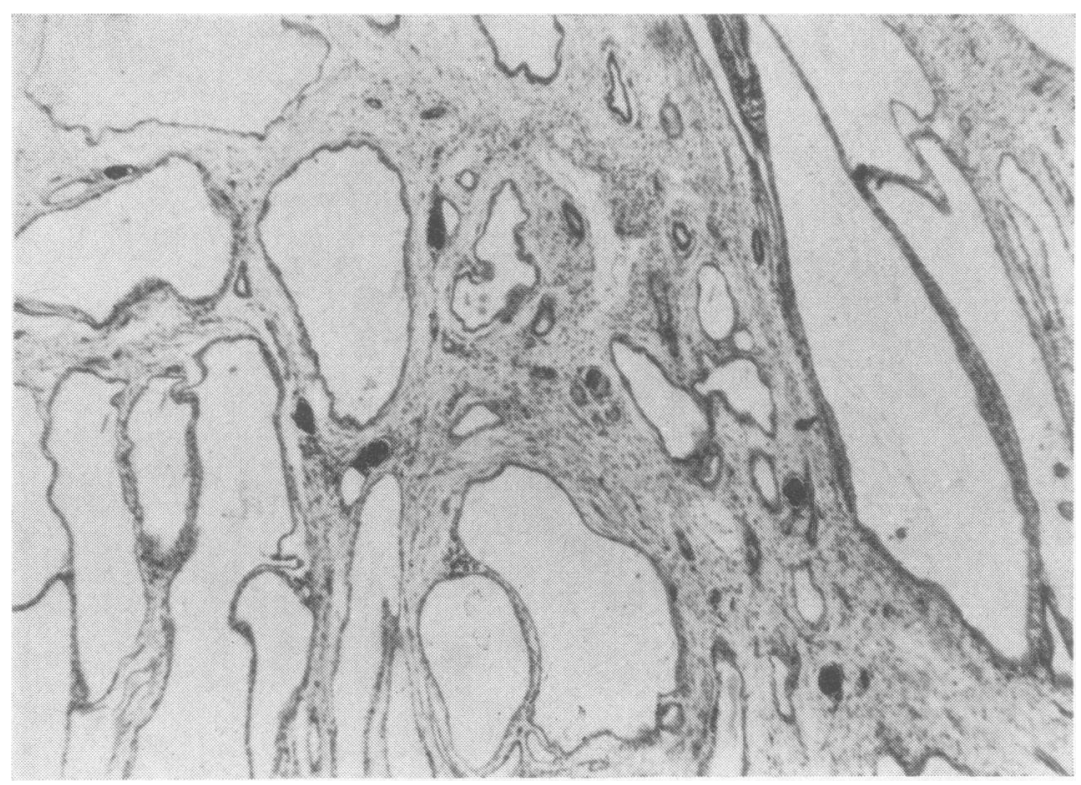

FIG. 5. Case 1. Kidney showing elongated oval cysts $(\times 45)$.

kidneys of an unusual type, malformation of the liver, atresia of the common bile duct, an occipital meningo-encephalocoele, and bilateral talipes equinovarus.

The liver. The liver was slightly enlarged (135 g; normal $105 \mathrm{~g}$ ). Microscopically there was striking proliferation of the bile duct structures with minimal dilatation (Fig. 7). These ducts were often cut longitudinally and appeared to encircle the portal tracts. The ductular epithelium was poorly differentiated, low cuboidal in type, and many structures had no visible lumen. The periportal connective tissue was moderately increased, but no intralobular fibrosis was observed. The portal tracts contained an unusually large number of vessels. The liver cells were normal in appearance, with no bile retention. Scattered foci of hematopoietic cells were seen.

The kidneys. Both kidneys were grossly enlarged (weight not recorded). Microscopically the cortex and medulla were undifferentiated and were filled with cysts of varying sizes lined with cuboidal epithelium. These cysts were round or square (Fig. 8) and were often clustered around glomerular elements as though they were derived from convoluted tubules. The connective tissue was extensive and dense, and formed concentric rings around some cysts. The remaining glomerular ele- ments lay in this fibrous tissue especially in the subcapsular region.

The glass plate reconstruction. The portal trace in Fig. 7 was reconstructed and is shown in Figure 9. There were two broken rings of longitudinally cut ducts within the portal tract-an inner ring lying well within the portal tract and an outer ring lying close to the periphery. A lumen was usually visible in the ducts forming the outer circle, but not in the inner circle. Many radial ducts joined the outer and inner rings, and the outer ring communicated with the limiting plate via small ductules which joined with the canaliculi. No main interlobular duct was seen.

\section{Congenital hepatic fibrosis (CHF)}

Case 3. This liver lesion was an incidental finding in a $2 \frac{1}{2}$-year-old girl who died of widespread thromboses in large veins for which no explanation was found.

The liver. The liver was markedly enlarged, weighing $600 \mathrm{~g}$ (normal 394-418 g). Microscopically the portal tracts were very prominently enlarged and fibrous, and the connective tissue stained with PAS even after diastase treatment. There was moderate periportal and interlobular fibrosis with bridging of adjacent portal tracts, and the lobules varied in size. The basic lobular 
pattern was maintained, though somewhat distorted. No intralobular fibrosis was apparent.

The portal tracts contained many bile ducts and ductules of varying shapes and sizes (Fig. 10), all of which were mildly dilated. The larger ducts near

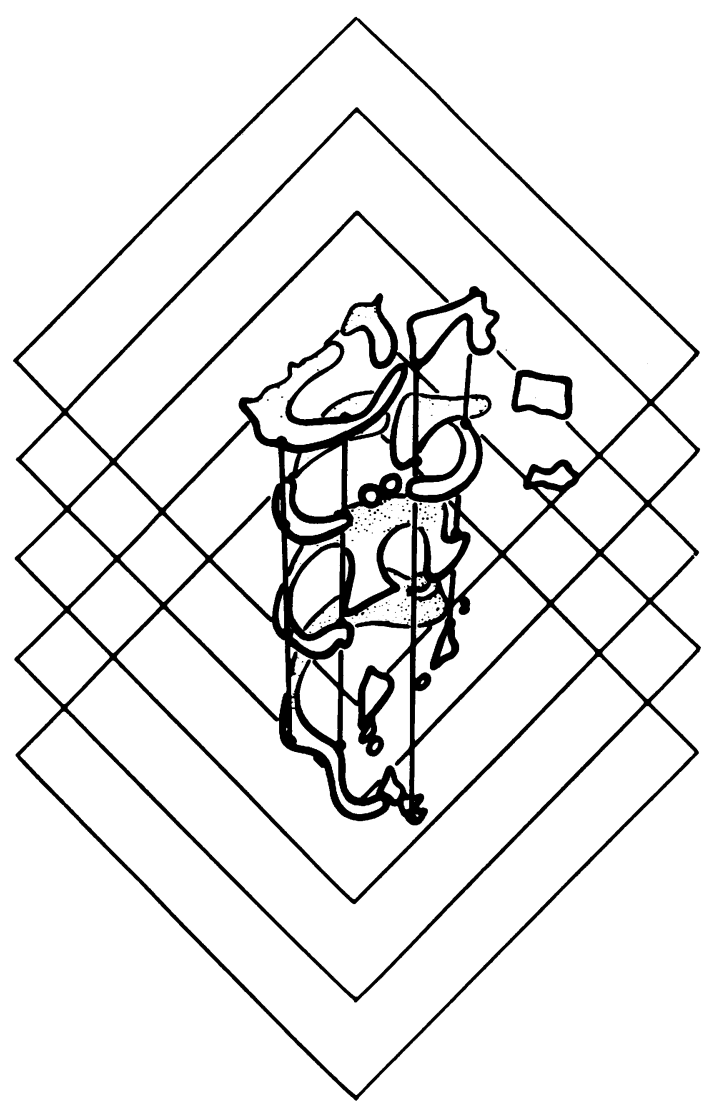

FIG. 6. Line diagram traced from glass plates of every 10th section of a portal tract from case 1 showing irregularly dilated ducts running longitudinally at the periphery of the portal tract. These ducts anastomose so extensively that they almost form a single annular channel. the axis of the portal tracts showed infolding, but the smaller peripherally placed ducts were oval in shape. Areas of ductular proliferation were also observed in the fibrous liver capsule and in the connective tissue around the central veins.

The central veins and hepatic arteries appeared normal in size and number. However the number of portal vein radicals in the medium and small sized portal tracts were reduced. The liver cells were normal except for foci of fatty vacuolation. No bile retention was observed.

The kidneys. The kidneys were slightly enlarged (right $75 \mathrm{~g}$, left $70 \mathrm{~g}$; normal right 47-58 g, left $46-49 \mathrm{~g}$ ). Microscopically the only abnormality was a minor degree of dilatation of some collecting tubules and convoluted tubules in the medulla.

The glass plate reconstruction. The portal tract in Fig. 10 was reconstructed and showed a very complex system of discrete ductules running longitudinally at the periphery of the portal tract, and a relatively normal main interlobular duct. The complexity of the duct network prevented precise identification of communications between them, and also made the reconstruction very difficult to photograph. The absence of bile retention in a child of this age proves that this network provides functionally adequate channels through which bile reaches the main interlobular duct.

Quantitative assessment of ducts. The results recorded in Table I confirm the impressions already described. The number of ducts was greatly increased in all three abnormal livers, but the increase was much more striking in case 2 than in either of the other cases. All classes of ducts seen in the normal liver were increased in number in CHF. However, the ducts seen in the two forms of IPD were so abnormal that it was difficult to apply normal terminology. In Table I these ducts are recorded in the category most appropriate to their

TABLE I

QUANTITATIVE ASSESSMENT OF BILE DUCTS

\begin{tabular}{|c|c|c|c|c|}
\hline $\begin{array}{c}\text { Numbers of Structures per } \\
\text { Portal Tract }\end{array}$ & Normal & Case 1 & Case 2 & Case 3 \\
\hline Large interlobular ducts & $1 \cdot 3 \pm 0.47$ & 0 & 0 & $4 \cdot 8 \pm 0.49$ \\
\hline $\begin{array}{l}\text { Ductules near periphery of } \\
\text { tract } \\
\text { Normal calibre } \\
\text { Dilated }\end{array}$ & $2 \cdot 3 \pm 0.19$ & $\stackrel{0}{4 \cdot 9 \pm 0.37}$ & $\begin{array}{r}44.1 \pm 0.58 \\
0.6 \pm 0.13\end{array}$ & $\begin{array}{c}0 \\
13.9 \pm 0.93\end{array}$ \\
\hline $\begin{array}{l}\text { Communicating ductules in } \\
\text { limiting plate }\end{array}$ & $2 \cdot 6 \pm 0 \cdot 16$ & $12 \cdot 1 \pm 0 \cdot 58$ & $6.0 \pm 0.32$ & $11 \cdot 0 \pm 0.89$ \\
\hline Total & $6 \cdot 1 \pm 0 \cdot 25$ & $20 \cdot 9 \pm 1 \cdot 01$ & $50.7 \pm 0.52$ & $29 \cdot 7 \pm 2 \cdot 12$ \\
\hline
\end{tabular}




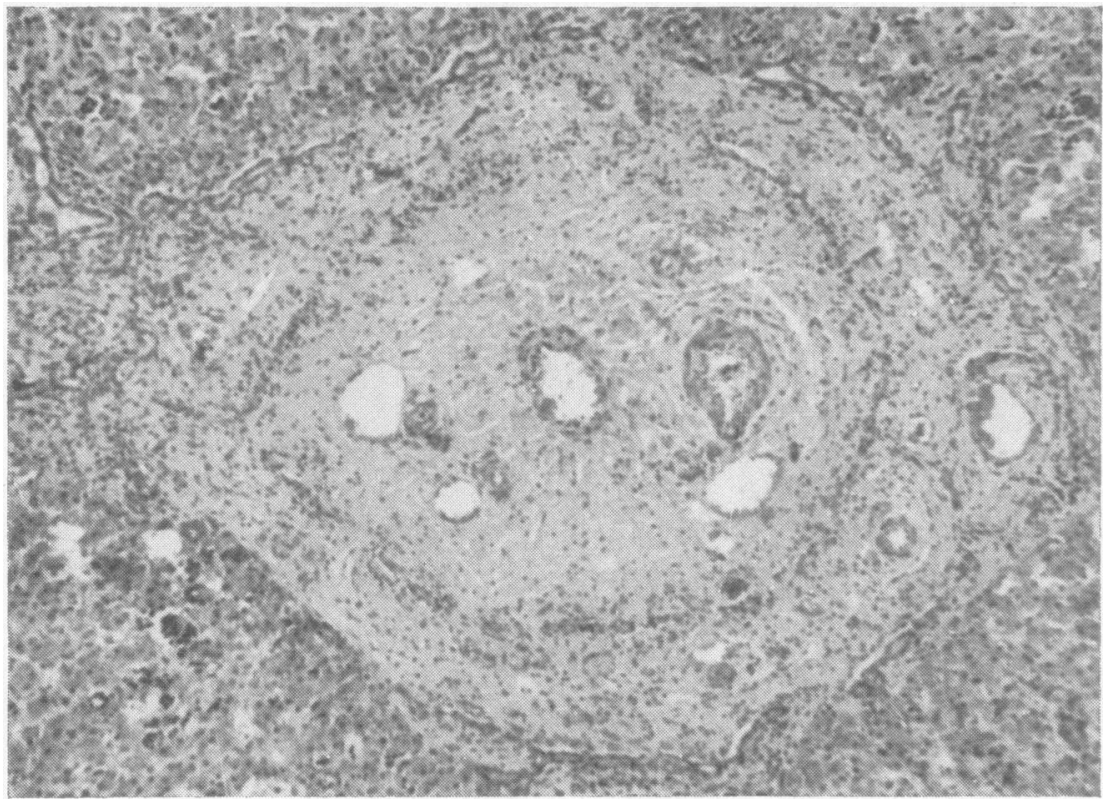

FIg. 7. Case 2. The portal tract which was reconstructed. Many bile ducts are cut longitudinally and appear to encircle the portal tract $(\times 90)$.

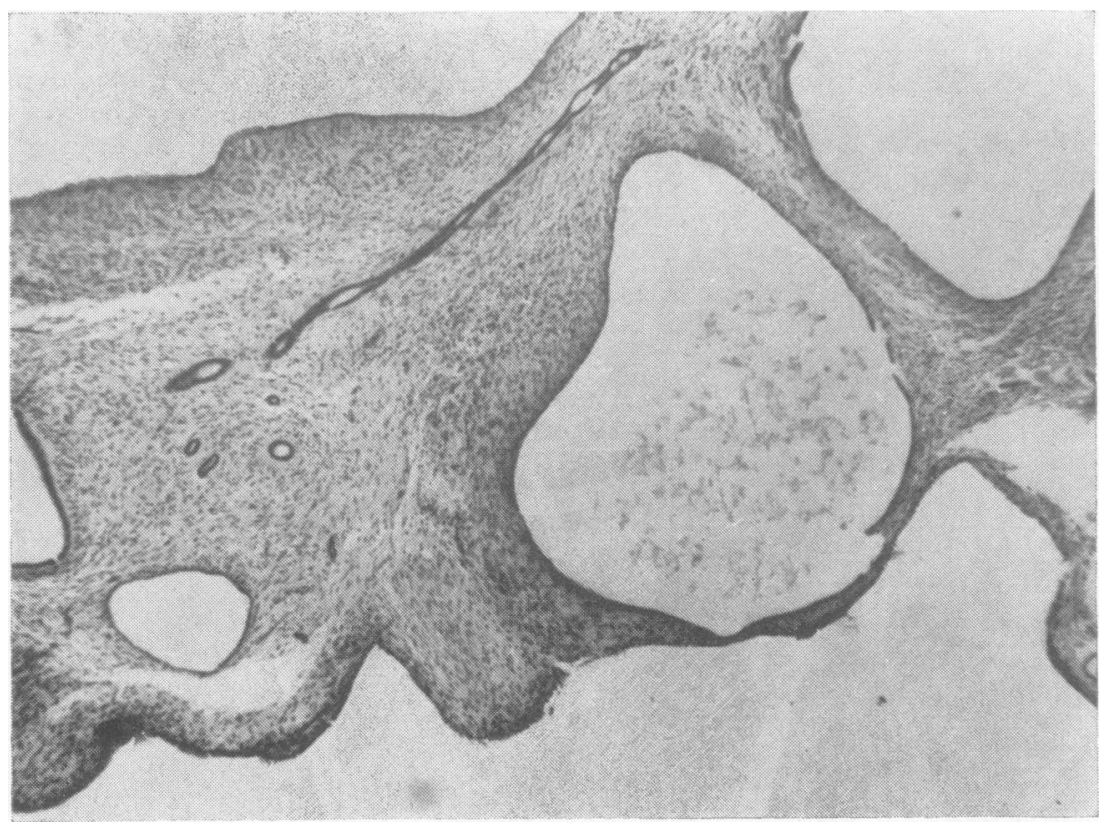

Fig. 8. Case 2. Kidney showing round or square cysts and extensive connective tissue $(\times 130)$. 


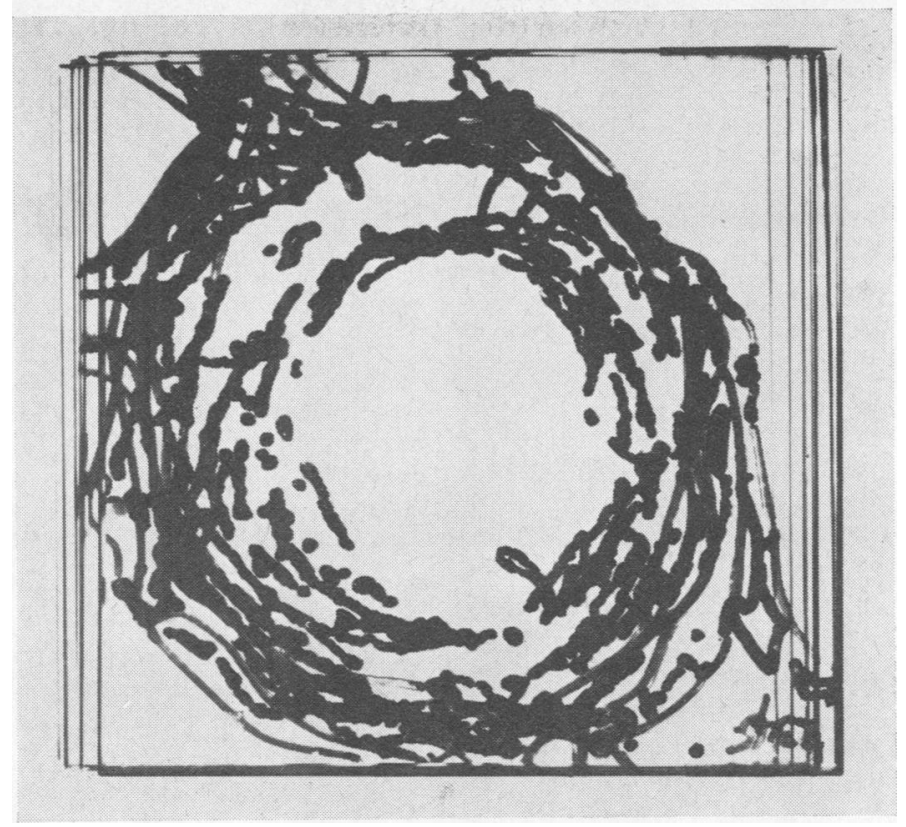

FIG. 9. Axial photograph of plates traced from every 10th section of a portal tract from case 2 showing two broken rings of longitudinally cut ducts.

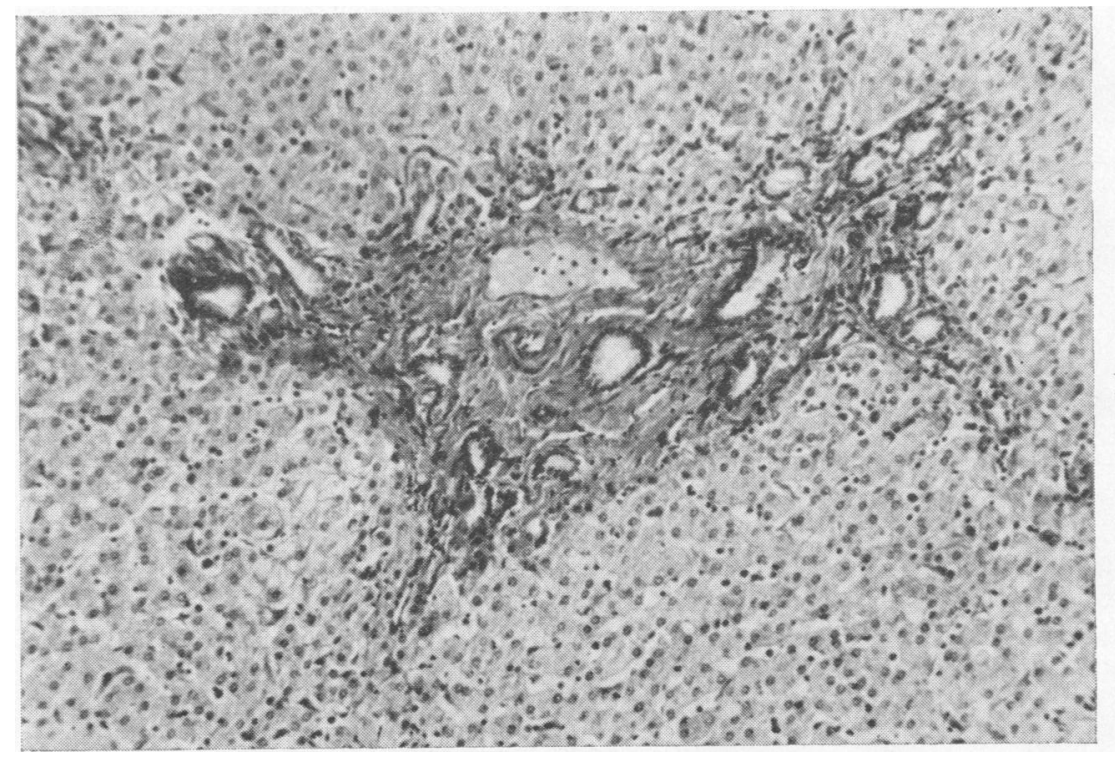

FIg. 10. Case 3. Portal tract which was reconstructed. The number of bile ducts present is increased but they are only mildly dilated $(\times 130)$. 
anatomical position. The contrast between the large dilated ductules in case 1 and the numerous small ductules in case 2 is very obvious in these figures.

\section{Discussion}

The main purpose of this paper is to emphasize the need for three-dimensional study of the bile duct anatomy in the infantile polycystic diseases of the kidney and liver. The importance of microdissection of the kidney has been acknowledged for some time, but few authors have applied a similar level of precision to the study of the accompanying liver lesion. No attempt is made to propose a new classification because too few cases have been studied. There is such confusion in the literature that no new classification should be put forward until a large series of cases has been studied adequately. This will require either reconstruction or microinjection of portal tracts and microdissection of the kidney in each case, as well as ascertainment of cases by some method which gives proper perspective regarding frequency and inheritance of each disease.

It is, however, clear that CHF differs from IPD in the type of liver lesion and renal lesion, and not just in the degree of these abnormalities. Failure to distinguish between these diseases has been an important source of confusion in the literature (Kerr et al, 1961; Blyth and Ockenden, 1971; Jorgensen, 1971). All orders of bile ducts and ductules are increased in number and in calibre, and the kidney is only very mildly affected with dilatation of the medullary collecting tubules in CHF.

The lesions seen in case 1 and case 2 clearly represent two different forms of IPD. A third distinct form was seen in one baby who was excluded from detailed study (see above).

The entity designated as group 2 (case 2 and four other babies) is the more easily defined. The liver shows portal fibrosis and proliferation of circularly running ductules without dilatation. The main interlobular duct is absent. The kidneys are fibrous and the cysts appear round or square. The dilatation has been shown to be greatest in the proximal convoluted tubules in two other babies in this group in an independent study in 1971 (L. Cussen and T. J. Baxter, personal communication). An occipital encephalocoele completes the syndrome, which may also include talipes and cleft palate. This combination corresponds to the syndrome described by Meckel (1822). Jorgensen (1971) recently reported elegant studies of the liver in a similar case, but unfortunately used the term con- genital hepatic fibrosis. The presence of two sib pairs in this group is in accord with previous evidence of autosomal recessive inheritance.

The uniformity of the five cases in group 1 is less easy to prove. The liver and kidney lesions appeared similar in routine sections in all cases, but material adequate for reconstruction was available from only one patient. Microdissection of the kidney of another patient in this group has been reported previously by Baxter (1965, case 16), and showed gross cystic dilatation of collecting tubules. In routine sections the renal cysts are elongated radially and accompanied by little fibrosis. The liver lesion comprises moderate proliferation and striking dilatation of the longitudinally running ductules at the periphery of the portal tracts. The absence of the main interlobular ducts, and the degree of dilatation and confluence of the ductules, distinguish this liver lesion from that in CHF, with which it might be confused in routine sections. Consideration of the renal lesion should also prevent this error.

Unfortunately, few reported series have been collected in a fashion which allows estimation of the absolute frequency of IPD, or the relative frequency of different forms. The 11 babies ascertained were born in Victoria in 10 years. If it were assumed that all cases were found, the frequency would be approximately 1 in 60,000 births. This is clearly a minimum estimate. Another estimate of 1 in 20,000 births is obtained by using only those occurring in the teaching obstetric hospitals (six cases). The true incidence must lie between these figures.

Those forms of IPD which allow survival beyond the newborn period appear to be more rare than other studies might suggest (Blyth and Ockenden, 1971) for only one such patient has been seen in the 10-year period.

Grateful appreciation is extended to Dr J. Philpott who ascertained the cases, to Dr E. Abrahams, Queen Victoria Memorial Hospital and Dr D. Fortune, Royal Women's Hospital who provided material and relevant clinical details of the cases, and to $\mathrm{Dr} \mathrm{T}$. Baxter who gave assistance in the interpretation of kidney histology from her microdissection studies of some cases.

\section{REFERENCES}

Baxter, T. J. (1965). Cysts arising in the renal tubules. Archives of Disease in Childhood, 40, 464-473.

Blyth, H. and Ockenden, B. (1971). Polycystic disease of kidneys and liver presenting in childhood. Fournal of Medical Genetics, 8, 257-284.

Elkin, M. and Bernstein, J. (1969). Cystic disease of the kidneyradiological and pathological considerations. Clinical Radiology, 20, 65-82. 
Ivemark, B. I., Oldfelt, V., and Zetterström, R. (1959). Familial dysplasia of kidneys, liver and pancreas. A probably gentically determined syndrome. Acta Pediatrica, 48, 1-11.

Jorgensen, M. (1971). A case of abnormal intrahepatic bile duct arrangement submitted to three dimensional reconstruction. Acta Pathologica et Microbiologica Scandinavica, Section A. 79, 303306.
Kerr, D. N. S., Harrison, C. V., Sherlock, S., and Walker, R. M (1961). Congenital hepatic fibrosis. Quarterly fournal of Medicine, 30, 91-118.

Meckel, J. F. (1822). Beschreibung zweier, durch sehr ähnliche Bildungsabweichungen entstellter Geschwister. Deutsches Archiv fïr die Physiologie, 7, 99-172.

Osathanondh, V. and Potter, E. (1964). Pathogenesis of polycystic kidneys. Archives of Pathology, 77, 459-512.

\section{Announcement}

Internationally known investigators will gather for a two-day Symposium on Nutrition and Ageing, sponsored by the Institute of Human Nutrition of Columbia University, College of Physicians and Surgeons, at the Commodore Hotel, Lexington Avenue, 42nd Street, New York City, on 21 and 22 November 1974.

The purpose of this meeting is to review the important information pertaining to nutrition and the processes involved in ageing; to examine in depth the effects of nutrition on diets of the elderly; to explore those areas where new research is occurring and where more research is needed; to document the way in which nutritional services are being brought to elderly and the ways in which improvement can be made.

For further information write to the Symposium Chairman: Dr Myron Winick, Director, Institute of Human Nutrition, Columbia University, 511 West 166th Street, New York, NY 10032, USA. 